\title{
Structural insights into translational recoding by frameshift suppressor tRNA ${ }^{\text {Suff }}$
}

\author{
CRYSTAL E. FAGAN, TATSUYA MAEHIGASHI, JACK A. DUNKLE, STACEY J. MILES, and CHRISTINE M. DUNHAM \\ Department of Biochemistry, Emory University School of Medicine, Atlanta, Georgia 30322, USA
}

\begin{abstract}
The three-nucleotide mRNA reading frame is tightly regulated during translation to ensure accurate protein expression. Translation errors that lead to aberrant protein production can result from the uncoupled movement of the tRNA in either the $5^{\prime}$ or $3^{\prime}$ direction on mRNA. Here, we report the biochemical and structural characterization of $+\mathbf{1}$ frameshift suppressor tRNA ${ }^{\text {Sufj }}$, a tRNA known to decode four, instead of three, nucleotides. Frameshift suppressor tRNA ${ }^{\text {Sufj }}$ contains an insertion $5^{\prime}$ to its anticodon, expanding the anticodon loop from seven to eight nucleotides. Our results indicate that the expansion of the anticodon loop of either ASL ${ }^{\text {Sufj }}$ or tRNA ${ }^{\text {Sufj }}$ does not affect its affinity for the A site of the ribosome. Structural analyses of both ASL ${ }^{\text {Sufj }}$ and $\mathrm{ASL}^{\text {Thr }}$ bound to the Thermus thermophilus $70 \mathrm{~S}$ ribosome demonstrate both ASLs decode in the zero frame. Although the anticodon loop residues 34-37 are superimposable with canonical seven-nucleotide ASLs, the single C31.5 insertion between nucleotides 31 and 32 in $\mathrm{ASL}^{\text {Sufl }}$ imposes a conformational change of the anticodon stem, that repositions and tilts the ASL toward the back of the A site. Further modeling analyses reveal that this tilting would cause a distortion in full-length A-site tRNA ${ }^{\text {Sufj }}$ during tRNA selection and possibly impede gripping of the anticodon stem by $16 \mathrm{~S}$ rRNA nucleotides in the P site. Together, these data implicate tRNA distortion as a major driver of noncanonical translation events such as frameshifting.
\end{abstract}

Keywords: ribosome; mRNA; reading frame; anticodon stem-loop; decoding; X-ray crystal structure

\section{INTRODUCTION}

The accurate translation of the genetic code into properly folded and active proteins is crucial to cellular survival. Errors in protein synthesis can result in misfolded or truncated proteins that trigger protein degradation pathways and even cellular apoptosis (Manley et al. 1978; Nangle et al. 2002; Lee et al. 2006). Translation of a triplet nucleic acid sequence on mRNA into 20 different amino acids is carried out by the ribosome with high fidelity $\left(10^{-4}-10^{-3}\right)$ where missense errors, or tRNA misincorporation, account for the majority of this error rate ( 1 in 3000 residues) (Edelmann et al. 1977; Bouadloun et al. 1983; Kramer et al. 2007). While processivity errors, such as changes in the mRNA reading frame, occur much less frequently ( 1 in 30,000 amino acids incorporated), they are considered to be more detrimental than missense errors because they often prevent the production of a full length, functional protein (Kurland 1992). In organisms with a nearly equal genomic GC and AT nucleotide frequency, like Escherichia coli, out-of-frame stop codons occur roughly every 20 codons resulting in the rapid termination of translation following a frameshift error (Jorgensen and Kurland 1990; Kurland 1992). While much is known about the prevention of missense errors by ribosomal proofreading

Corresponding author: christine.m.dunham@emory.edu

Article published online ahead of print. Article and publication date are at http://www.rnajournal.org/cgi/doi/10.1261/rna.046953.114. mechanisms (Zaher et al. 2009; Rodnina 2012), how the ribosome maintains the mRNA reading frame is still poorly understood.

Genetic suppressor experiments in Saccharomyces cerevisiae and Salmonella typhimurium first demonstrated the three-nucleotide genetic code could be altered (Riyasaty and Atkins 1968; Riddle and Roth 1970; Yourno 1970, 1972; Sherman et al. 1974). Extragenic mutations in tRNAs were found to compensate for insertions or deletions in the genetic code by noncanonical decoding of a non-three-nucleotide codon (for review, see Roth 1974). The first sequenced external suppressor of a genetically encoded frameshift (sufD) was a cytosine insertion immediately $5^{\prime}$ of the tRNA ${ }^{\text {Gly }}$ anticodon $\left(5^{\prime}-\right.$ CCC- $3^{\prime}$; all codons and anticodons are shown $5^{\prime}-3^{\prime}$ ) between position 33 and 34 (Riddle and Carbon 1973). Because this particular frameshift suppressor expanded the glycine codon to GGG-G (first three nucleotides denote a glycine codon with the additional nucleotide preceded by a hyphen and underlined), the Watson-Crick complementarity between the cytosine insertion in the anticodon loop and the extra guanine in the codon suggested a four-base interaction between the tRNA-mRNA pair could form (Bossi and Roth 1981).

(C) 2014 Fagan et al. This article is distributed exclusively by the RNA Society for the first 12 months after the full-issue publication date (see http:// rnajournal.cshlp.org/site/misc/terms.xhtml). After 12 months, it is available under a Creative Commons License (Attribution-NonCommercial 4.0 International), as described at http://creativecommons.org/licenses/by-nc/4.0/. 
Many frameshift suppressor tRNAs were subsequently found to contain similar complementarity between insertions in anticodon stem-loops (ASLs) and suppressible four-nucleotide codons, providing strong evidence for a quadruplet or fourbase decoding model (Fig. 1A; Riyasaty and Atkins 1968; Riddle and Roth 1972; Yourno 1972; Prather et al. 1981; Cummins et al. 1982). In addition, optimal frameshift suppression resulting in higher frameshift efficiencies occurred from a four-nucleotide Watson-Crick base-pair interaction (Yarus 1982; Gaber and Culbertson 1984; Curran and Yarus 1987; Moore et al. 2000; Anderson et al. 2002).

The first exception to this quadruplet decoding model came with the identification of frameshift suppressor tRNA ${ }^{\text {Suff }}$, a modified tRNA ${ }_{3}^{\text {Thr }}$ (GGU) containing a cytosine insertion in the anticodon loop between nucleotides C31 and U32, rather than adjacent to the anticodon (Fig. 2; Bossi and Smith 1984). The C31.5 insertion allows tRNA ${ }^{\text {Suff }}$ to decode four nucleotide codons (ACC- $\underline{A}, A C C-\underline{C}$, and ACC- $\underline{\text { U }}$ ) as a single threonine, to restore the correct reading frame in a number of histidine biosynthesis gene derivatives such as hisA, hisC, hisF, and hisG (Bossi and Roth 1981). While the variability in the additional nucleotide of the codon that frameshift suppressor tRNA ${ }^{\text {Suff }}$ decodes strongly suggests that a direct interaction between the additional nucleotide of the tRNA is not necessary for +1 suppression, it is unclear how an insertion

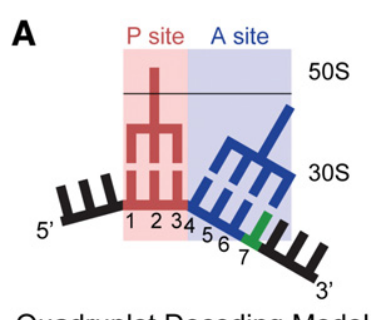

Quadruplet Decoding Model

C

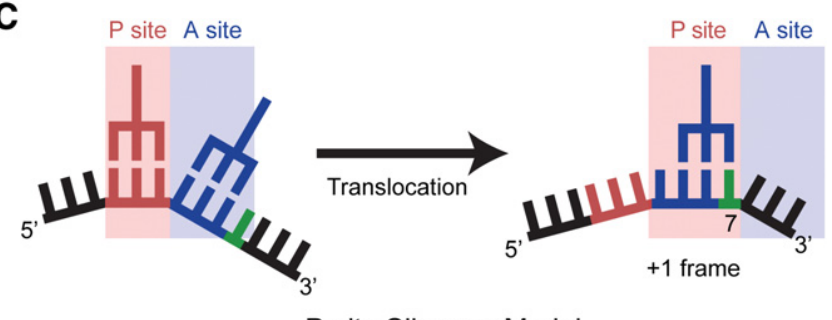

P-site Slippage Model

FIGURE 1. Possible models for +1 frameshifting resulting from an eight-nucleotide anticodon stem-loop. (A) The quadruplet decoding model posits that insertions in the anticodon stem-loop of a frameshift suppressor tRNA leads to a four-nucleotide anticodon capable of decoding and translocating a four-nucleotide mRNA codon (with the extra nucleotide shown in green). The numbering of the mRNA begins with the first position in the $\mathrm{P}$ site. $(B)$ An alternative model is that the nucleotide insertion in the anticodon stem-loop causes a widening of the loop, allowing the anticodon nucleotide 34 to interact with the fourth nucleotide of the A-site codon (green; numbered as 7 in $A$ ). (C) In the P-site slippage model, normal decoding in the zero frame occurs in the A site; however, the transition into the +1 frame occurs after translocation to the $\mathrm{P}$ site due to a weakened interaction between the anticodon and codon.
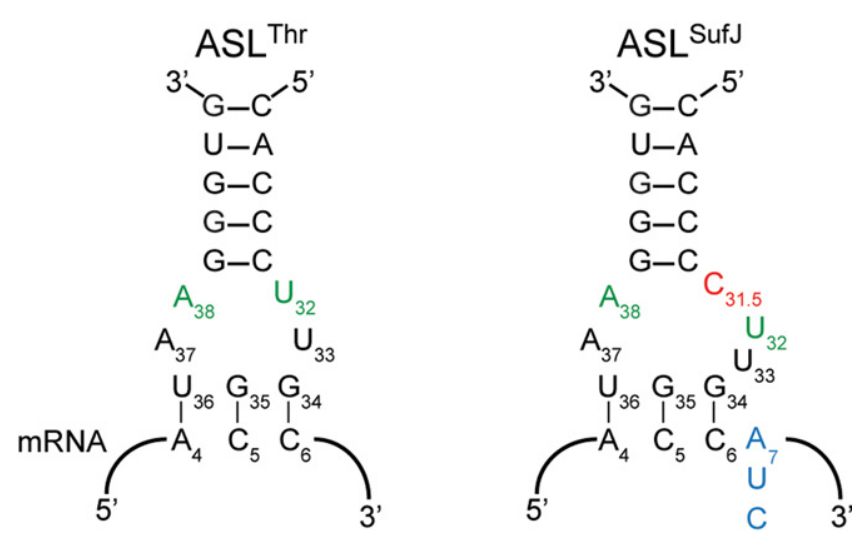

FIGURE 2. Frameshift suppressor tRNA ${ }^{\text {SufJ }}$ is a derivative of tRNA ${ }^{\text {Thr }}$. Secondary structure representation of the anticodon stem-loops of tRNA $^{\text {Thr }}$ and frameshift suppressor tRNA ${ }^{\text {Suff }}$ interacting with their respective codons. The C31.5 insertion (red) in $\mathrm{ASL}^{\text {Suff }}$ is $5^{\prime}$ to the anticodon nucleotides 34,35 , and 36 causing the codon to increase from three to four nucleotides (blue). The conserved U32.A38 interaction (green) in tRNA $^{\text {Thr }}$ may be altered in tRNA ${ }^{\text {Suff }}$ due to the insertion.

within the anticodon loop, but distant from the anticodon, could expand the size of the codon. Because of the unique location of the insertion and apparent lack of Watson-Crick complementarity, it was proposed that tRNA ${ }^{\text {SufJ }}$ mediated +1 frameshifting through a distinct mechanism (Bossi and Smith 1984).

More recent work has resulted in two additional models for +1 frameshifts. The first model was derived from X-ray crystal structures of $30 \mathrm{~S}$ bound to ASLs containing eight-nucleotide loops. These ASLs were not identified by suppressor studies but rather, were optimized for unnatural amino acid incorporation exploiting +1 frameshift decoding (Hohsaka et al. 2001). These structures revealed a noncanonical ASL conformation where widening of the anticodon loop allows for three nucleotides of the ASL to extend over four nucleotides of the codon in the A site (Fig. 1B; Dunham et al. 2007). An additional model was proposed after the identification of tRNA ${ }^{\text {SufJ }}$ and other subsequent suppressors such as tRNA $^{\text {SufA6 }}$ and suf16 tRNA mutations, where the shift into the new mRNA frame was not dependent upon forming Watson-Crick interactions in the A site (Fig. 1C; Gaber and Culbertson 1984; Qian et al. 1998). Instead, these studies indicated that frameshift efficiencies were heavily influenced by the next incoming tRNA, implying the frameshift in these particular cases, occurs in the P site (Farabaugh 2000; Atkins and Bjork 2009; Nasvall et al. 2009). Given these distinct models, it has remained unclear whether a single, unified model could explain all types of +1 frameshifting facilitated by suppressor tRNAs.

Here, we present biochemical and structural studies of frameshift suppressor tRNA ${ }^{\text {Suff }}$ to elucidate how this suppressor decodes a four-nucleotide codon in the A site. We performed affinity experiments to determine the effect of the $\mathrm{C} 31.5$ insertion on the ability of either $\mathrm{ASL}^{\text {Suff }}$ or 
tRNA $^{\text {Sufj }}$ to recognize an A-site codon. We next solved five X-ray crystal structures of the ASLs of tRNA ${ }^{\text {Suf }}$ and tRNA ${ }^{\text {Thr }}$ bound to the A site of the Thermus thermophilus (Tth) 70S ribosome. Our molecular insights reveal that the conformational distortions present in frameshift suppressor tRNAs likely promote +1 frameshifting.

\section{RESULTS}

\section{The nucleotide insertion $5^{\prime}$ of the anticodon minimally alters affinity for the $\mathrm{A}$ site}

Expanded ASLs containing insertions $5^{\prime}$ of the anticodon show lower affinities than wild-type tRNAs for the ribosomal A site (Walker and Fredrick 2006). Therefore, as a first step in understanding the behavior of tRNA ${ }^{\text {SufJ }}$ on the ribosome, we asked whether the expanded ASL of tRNA ${ }^{\text {SufJ }}$ affects its ability to form stable, high affinity codon-anticodon interactions in the A site, typical of a canonical tRNA interacting with a cognate codon. We performed affinity binding experiments with $\mathrm{ASL}^{\text {SufJ }}$ and $\mathrm{ASL}^{\text {Thr }}$ using E. coli $70 \mathrm{~S}$ ribosomes programmed with a P-site tRNA ${ }^{\mathrm{fMet}}$ containing either an ACC-A, ACC-U or ACC-C codon in the A site (Fig. 3). $\left[{ }^{32} \mathrm{P}\right]-\mathrm{ASL}^{\text {Suff }}$ was incubated with increasing amounts of $70 \mathrm{~S}$ ribosomes and applied to nitrocellulose filters to determine the amount of ASL ${ }^{\text {Sufj }}$ bound. While ASL ${ }^{\text {Suf }}$ bound to the A site of the ribosome with an apparent dissociation constant $\left(K_{\mathrm{D}}\right)$ of 85 and $76 \mathrm{nM}$ for the ACC-A and ACC-U codons, respectively, $\mathrm{ASL}^{\text {Sufj }}$ had a slight decrease in affinity for the ACC-C codon (130 nM) (Fig. 3A-C; Table 1). These $K_{\mathrm{D}}$ values are all within the previously reported range for tRNA or ASL binding to the A site ( $K_{\mathrm{D}}$ s between 33 and $500 \mathrm{nM}$ ) (von Ahsen et al. 1997; Phelps et al. 2002; Walker and Fredrick 2006). The antibiotic paromomycin preferentially enhances the affinity of cognate ASLs ( $\sim 15$ fold) while only modestly enhancing the affinity of near-cognate ASLs (approximately twofold) (Ogle et al. 2002). Our results indicate that paromomycin increases the $K_{\mathrm{D}}$ approximately six- to eightfold for all three +1 suppressible codons, consistent with a cognate interaction between the anticodon of $\mathrm{ASL}^{\text {SufJ }}$ and the +1 codons. If the interaction in the A site was in the +1 mRNA frame, then the addition of paromomycin should not affect the $K_{\mathrm{D}}$ for the ACC-A codon given that the interaction would be noncognate (U36-C5 and G34-A7 mismatches) (Fig. 2). These data provide initial support for a model where the interaction between $\mathrm{ASL}^{\text {Suf }}$ and all three +1 suppressible codons is cognate suggesting ASL ${ }^{\text {Sufj }}$ is bound in the zero or normal frame.

To assess whether the 31.5 insertion in $\mathrm{ASL}^{\text {Sufj }}$ affects A-site binding, we next measured the binding of $\mathrm{ASL}^{\mathrm{Thr}}$ to all three +1 suppressible codons in the presence or absence of paromomycin (Table 1). Similar $K_{\mathrm{D}}$ trends were observed, with $\mathrm{ASL}^{\text {Thr }}$ having a lower affinity for ACC-C $(310 \mathrm{nM})$ compared with the ACC-A and ACC-U codons (150 and $160 \mathrm{nM}$, respectively) (Fig. 3D-F). These data indicate the $\mathrm{C} 31.5$ insertion in ASL ${ }^{\text {Sufj }}$ does not lower the affinity as might have been expected of the ASL for the three codons, but instead, slightly increases the affinity.
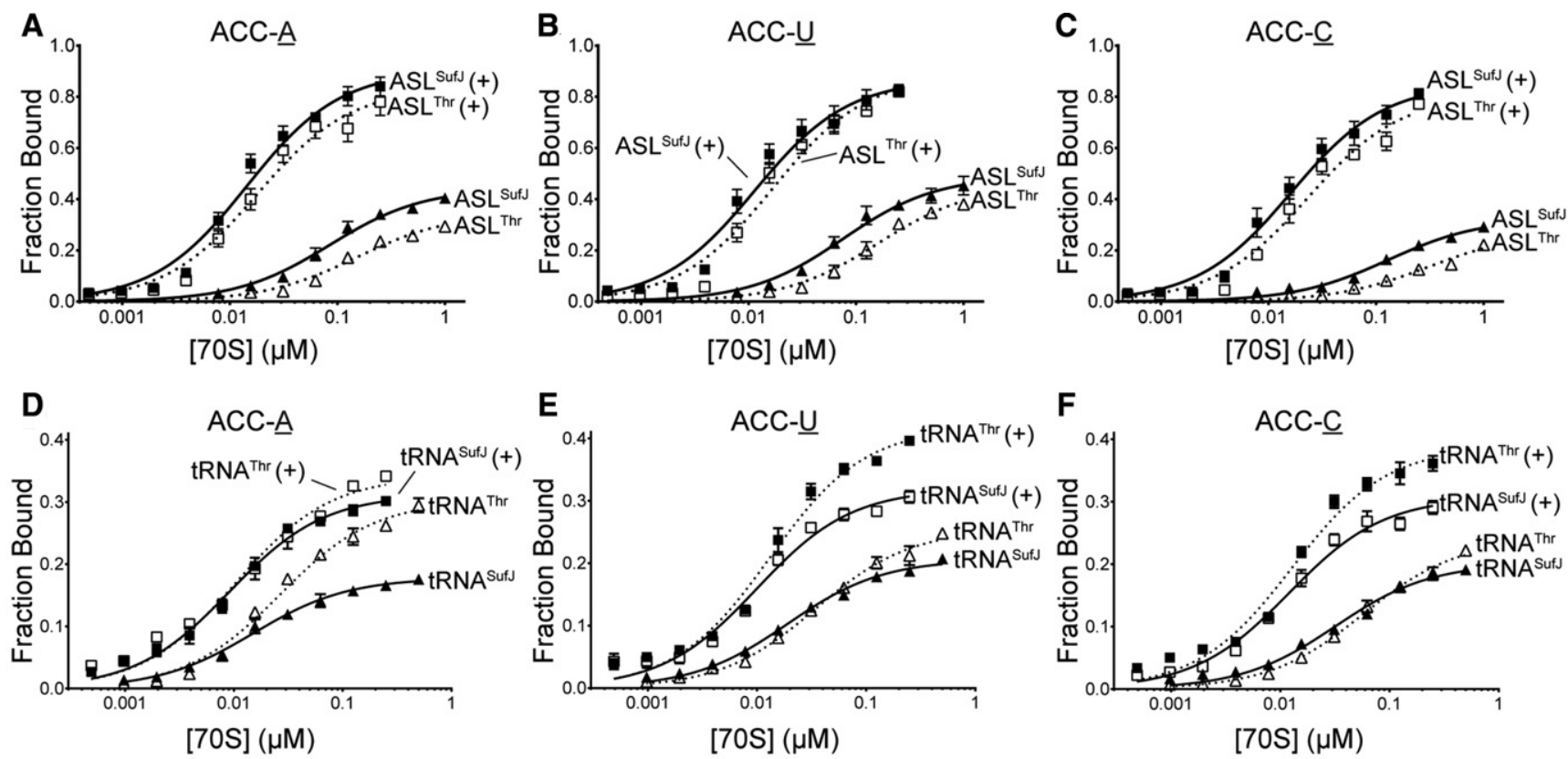

FIGURE 3. A-site binding of $\mathrm{ASL}^{\text {Suff }}, \mathrm{ASL}^{\mathrm{Thr}}$, $\mathrm{tRNA}^{\text {Suff }}$, and $\mathrm{tRNA}^{\mathrm{Thr}}$. Increasing concentrations of $70 \mathrm{~S}$ ribosomes were programmed with A-site co-

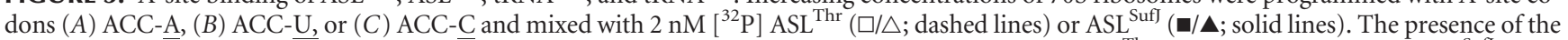
antibiotic paromomycin is indicated by "+". Similar binding experiments were also performed with tRNA ${ }^{\text {Thr }}\left(\square / \triangle\right.$; dashed lines) or tRNA ${ }^{\text {SufJ }}(\mathbf{\square} / \mathbf{\Delta}$; solid lines) with A-site codons $(D)$ ACC- $\underline{\mathrm{A}},(E)$ ACC- $\underline{\mathrm{U}}$, or $(F)$ ACC- $\underline{\mathrm{C}}$ in the presence or absence of paromomycin (indicated by “+”). 
TABLE 1. Binding affinity of tRNAs or ASLs to the A site of ribosomes programmed with different mRNA codons

\begin{tabular}{|c|c|c|c|c|}
\hline A-site codon & tRNA ${ }^{T h r}$ & tRNA ${ }^{\text {Sufj }}$ & $\mathrm{ASL}^{\mathrm{Thr}}$ & $\mathrm{ASL}^{\text {Sufj }}$ \\
\hline ACC-ㅡㅡ & $27,0.30$ & $15,0.18$ & $150,0.35$ & $85,0.44$ \\
\hline $\mathrm{ACC}-\underline{\bar{A}},+$ paro & $10,0.34$ & $9.2,0.31$ & $18,0.84$ & $14,0.90$ \\
\hline ACC- $\overline{-}$ & $58,0.24$ & $32,0.20$ & $310,0.27$ & $130,0.33$ \\
\hline ACC $-\bar{C},+$ paro & $13,0.39$ & $12,0.31$ & $23,0.81$ & $16,0.85$ \\
\hline ACC- $\underline{-}$ & $35,0.25$ & $19,0.21$ & $160,0.46$ & $76,0.49$ \\
\hline ACC $-\bar{U},+$ paro & $13,0.42$ & $10,0.32$ & $17,0.89$ & $11,0.87$ \\
\hline
\end{tabular}

Values correspond to $K_{\mathrm{D}}(\mathrm{nM})$ and $B_{\max }$. Binding experiments were also performed in the presence of $100 \mu \mathrm{M}$ paromomycin and denoted as "+ paro."

The binding of tRNA to the A site of the ribosome occurs with slightly higher affinities than ASLs due to other tRNA features that interact with the $50 \mathrm{~S}$ subunit such as the TYC loop, the D loop and the CCA tail (Jorgensen et al. 1985; Khade and Joseph 2010). To test whether tRNA ${ }^{\text {Suff }}$ exhibits the same trends in A-site binding as ASL ${ }^{\text {Suff }}$, namely an affinity indicative of a cognate codon-anticodon interaction slightly higher than $\mathrm{TRNA}^{\mathrm{Thr}}$, we again performed binding assays. Consistent with the observed ASL binding trends, tRNA ${ }^{\text {Sufj }}$ binds to each of the ACC-A, ACC-C, and ACC-U codons with approximately twofold tighter $K_{\mathrm{D}}(15-32 \mathrm{nM})$ than tRNA $^{\text {Thr }}(27-58 \mathrm{nM})$ (Table 1). Also consistent with our ASL binding studies, both tRNAs had similar dissociation constants for ACC-A and ACC- $-\underline{U}$ codons (tRNA ${ }^{\text {Suff }} 15$ and 19 $\mathrm{nM}$, respectively; $\mathrm{RNA}^{\mathrm{Thr}} 27$ and $35 \mathrm{nM}$, respectively), and a slightly weaker affinity for the ACC-C codon (tRNA ${ }^{\text {SufJ }}$ $32 \mathrm{nM}$; tRNA ${ }^{\text {Thr }} 58 \mathrm{nM}$ ). These results indicate that both suppressor ASL ${ }^{\text {Suff }}$ and tRNA ${ }^{\text {Suff }}$ follow general trends previously seen for other canonical tRNAs and provide further evidence that the expansion of the anticodon loop to eight nucleotides by the C31.5 insertion does not impede binding to cognate codons in the ribosomal A site.

\section{Structural determination of $\mathrm{ASL}^{\text {Sufj }}$ bound to +1 suppressible codons in the 70S A site}

To determine how tRNA ${ }^{\text {Suff }}$ decodes a four-nucleotide codon and understand how an expanded ASL is accommodated in the A site, we solved three X-ray crystal structures of $T$ th $70 \mathrm{~S}$ programmed with a P-site tRNA ${ }^{\mathrm{fMet}}$ and $\mathrm{ASL}^{\text {Suff }}$ bound to each of the following +1 suppressible codons: ACC-A, ACC- $\underline{\mathrm{C}}$, and ACC- $\underline{\mathrm{U}}$ (Fig. 4A; Supplemental Fig. S1; Table 2). The resolutions of the three structures ranged from 3.5 to $3.6 \AA$ and, in all three structures, un- biased $F_{\mathrm{o}}-F_{\mathrm{c}}$ difference electron density maps showed a clear signal for mRNA, P-site tRNA ${ }^{\text {fMet }}$, and A-site ASL $^{\text {Suff }}$ nucleotides 29-42 (Supplemental Fig. S2).

In the $70 S$ structure of ASL ${ }^{\text {Suff }}$ decoding an ACC-A codon in the absence of paromomycin, the three-nucleotide anticodon of $\operatorname{ASL}^{\text {Suff }}(34,35$, and 36) forms Watson-Crick base pairs with the first three nucleotides of the ACC codon in the zero frame (Fig. 4A). The structures of ASL ${ }^{\text {Suff }}$ bound to the ACC- $\underline{C}$ and ACC- $\underline{\mathrm{U}}$ codons in the presence of paromomycin reveal the same three Watson-Crick base-pair interactions between the codon and anticodon, indicating the antibiotic does not alter the A-site conformations (paromomycin was used to enhance the diffraction of these crystals) (Supplemental Fig. S1). In all three structures, there are no interactions with the fourth nucleotide of the A-site codon (position 7 of the mRNA) (Figs. 1, 4A; Supplemental Fig. S1). This lack of interaction is despite the potential to form a Watson-Crick base pair between the codon nucleotide A7 in the ACC-A codon and ASL nucleotide U33 (Fig. 2). Additionally, the presence of either an $\mathrm{A}, \mathrm{C}$, or $\mathrm{U} 3^{\prime}$ to the codon (fourth position of the A-site codon or denoted as A7, C7, or U7) does not alter the mRNA path (Supplemental Fig. S3). ASL $^{\text {Suff }}$ models in all three structures superimpose well, with a root mean square deviation of $0.25 \AA$, providing additional evidence that the ASL does not adopt different conformations depending upon the identity of the fourth nucleotide of the A-site codon. In summary, these structures confirm that the +1 frameshift mediated by tRNA ${ }^{\text {Suff }}$ does not occur during decoding in the A site and therefore, excludes the quadruplet decoding model (Fig. 1A).
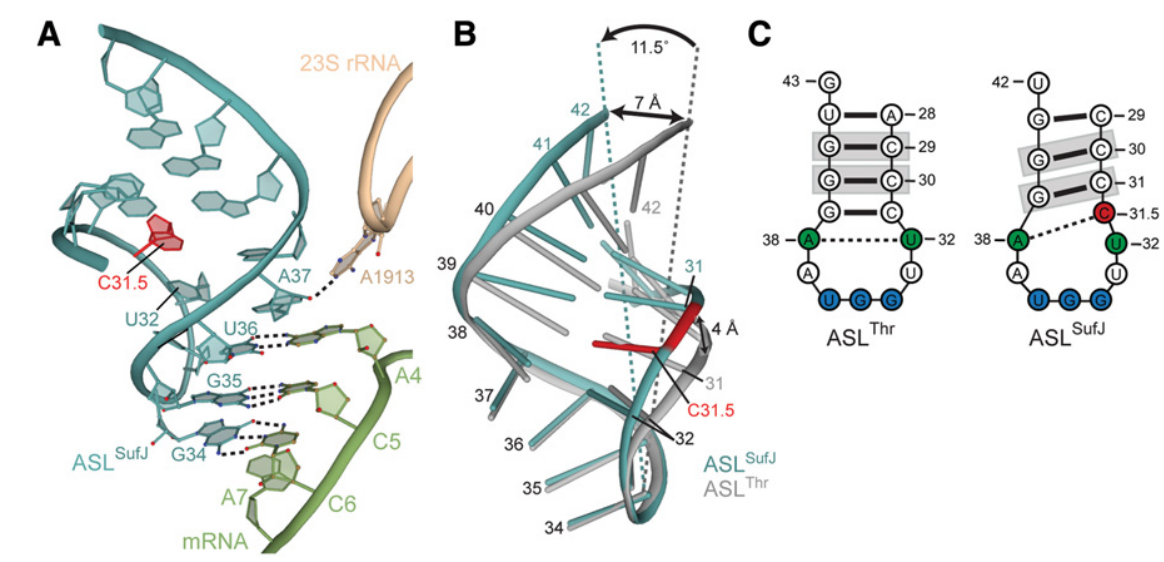

FIGURE 4. Conformation of ASL ${ }^{\text {Suff }}$ in the 70S A site. (A) $\mathrm{ASL}^{\text {Suff }}$ (blue) forms three WatsonCrick base pairs with three nucleotides of the ACC-A codon (green) in the zero frame (no paromomycin). Although the C31.5 insertion (red) increases the anticodon loop to eight nucleotides, the ASL is recognized as cognate with 23S rRNA nucleotide A1913 (tan) maintaining a hydrogen bond interaction with the $2^{\prime}-\mathrm{OH}$ of A37. (B) Overlay of ASL ${ }^{\text {Suff }}$ and $\mathrm{ASL}^{\text {Thr }}$ (gray) bound in the 70S A site shows the $\mathrm{C} 31.5$ insertion displaces the $5^{\prime}$ and $3^{\prime}$ phosphate backbone by $4 \AA$ and $7 \AA$, respectively. This narrowing of the major and minor grooves of ASL ${ }^{\text {Sufj }}$ also results in the entire stem tilting $11.5^{\circ}$ toward the back of the A-site decoding center. $(C)$ Secondary structure representation of ASL ${ }^{\mathrm{Thr}}$ and $\mathrm{ASL}^{\text {Sufj }}$ shows that the 31.5 insertion changes the conserved interaction between the U32.A38 (green) to C31.5 (red)·A38. The nucleotides that are gripped by $16 \mathrm{~S}$ rRNA residues G1338 and A1339 upon translocation to the P site are highlighted in gray. 
TABLE 2. Data collection and refinement statistics

\begin{tabular}{|c|c|c|c|c|c|}
\hline \multirow{2}{*}{$\begin{array}{l}\text { tRNA } \\
\text { mRNA }\end{array}$} & \multicolumn{3}{|c|}{$\mathrm{ASL}^{\text {Suff }}$} & \multicolumn{2}{|c|}{$\mathrm{ASL}^{\mathrm{Thr}}$} \\
\hline & ACC $-\underline{A}^{a}$ & ACC- $\underline{U}$ & ACC- $\underline{C}$ & ACC-A & ACC- $\underline{C}$ \\
\hline \multicolumn{6}{|l|}{ Data collection } \\
\hline Space group & $\mathrm{P} 2{ }_{1} 2{ }_{1} 2_{1}$ & $\mathrm{P} 2{ }_{1} 2{ }_{1} 2_{1}$ & $\mathrm{P} 2{ }_{1}{ }_{1} 2_{1}$ & $\mathrm{P} 2{ }_{1} 2{ }_{1} 2_{1}$ & $\mathrm{P} 2{ }_{1}{ }_{1} 2_{1}$ \\
\hline \multicolumn{6}{|l|}{ Cell dimensions } \\
\hline$a, b, c(\AA)$ & 209.4450 .7622 .3 & 210.8448 .9621 .6 & 210.5450 .7621 .1 & 209.0448 .7621 .0 & 209.0444 .6616 \\
\hline$\alpha, \beta, \gamma\left(^{\circ}\right)$ & 909090 & 909090 & 909090 & 909090 & 909090 \\
\hline Resolution $(\AA)$ & $50-3.6(3.7-3.6)$ & 50-3.5 (3.6-3.5) & $50-3.6(3.7-3.6)$ & $70-3.6(3.7-3.6)$ & $70-3.6(3.7-3.6)$ \\
\hline$R_{\text {sym }}(\%)$ & $28.7(125.1)$ & $23.1(114.7)$ & $18.7(90.8)$ & $21.5(89.9)$ & $18.7(90.5)$ \\
\hline$I / \sigma /$ & $7.3(1.6)$ & $5.7(1.2)$ & $7.8(1.9)$ & $6.8(1.8)$ & $7.3(1.7)$ \\
\hline Completeness (\%) & $99.2(99.6)$ & 99.7 (98.6) & $99.9(99.8)$ & $98.0(99.3)$ & $96.8(97.7)$ \\
\hline Redundancy & $6.6(6.4)$ & $5.8(4.8)$ & $5.3(5.1)$ & $4.1(4.1)$ & $3.4(3.4)$ \\
\hline \multicolumn{6}{|l|}{ Refinement } \\
\hline Resolution $(\AA)$ & $50-3.6$ & $50-3.5$ & $50-3.6$ & $70-3.6$ & $70-3.6$ \\
\hline No. of reflections & 668,466 & 725,686 & 674,544 & 656,584 & 636,863 \\
\hline$R_{\text {work }} / R_{\text {free }}(\%)$ & $21.4 / 25.3$ & $21.4 / 25.0$ & $20.5 / 24.4$ & $20.8 / 25.2$ & $21.7 / 25.9$ \\
\hline No. of atoms & 292,042 & 292,242 & 292,106 & 292,311 & 292,320 \\
\hline \multicolumn{6}{|l|}{ B-factors $\left(\AA^{2}\right)$} \\
\hline RNA & 104 & 99.6 & 103 & 79.7 & 96.0 \\
\hline Protein & 126 & 113 & 120 & 93.4 & 112.4 \\
\hline Ligand/ion & $66.4 / 62.6$ & $71.4 / 48.3$ & $71.5 / 49.2$ & $45.7 / 27.2$ & $51.8 / 40.7$ \\
\hline \multicolumn{6}{|l|}{ RMS deviations } \\
\hline Bond lengths $(\AA)$ & 0.006 & 0.006 & 0.006 & 0.006 & 0.006 \\
\hline Bond angles $\left({ }^{\circ}\right)$ & 0.959 & 0.923 & 0.983 & 1.007 & 1.002 \\
\hline
\end{tabular}

Values in parentheses are for highest-resolution shell.

${ }^{a}$ This structure was solved without paromomycin whereas all other structures contain paromomycin.

During decoding, 16S rRNA nucleotides A1492, A1493, and G530 monitor the minor groove of the codon-anticodon helix to probe for Watson-Crick base-pair geometry (Ogle et al. 2001; Demeshkina et al. 2013). These 16S rRNA residues form hydrogen bonds with the first and second nucleotide pairs of the codon-anticodon helix during cognate tRNA decoding (Ogle et al. 2001). In addition to canonical interactions with $16 \mathrm{~S}$ rRNA, 23S rRNA residue A1913 also forms a hydrogen bond with the $2^{\prime}-\mathrm{OH}$ of ASL ${ }^{\text {Suff }}$ nucleotide 37. All of these interactions are seen upon $\mathrm{ASL}^{\text {Suff }}$ decoding the ACC-A codon (in the absence of paromomycin), indicating the ribosome recognizes this interaction as cognate (Fig. $4 \mathrm{~A})$. The $70 \mathrm{~S}$ structures of $\mathrm{ASL}^{\mathrm{Suff}}$ bound to the ACC-C and ACC- $\underline{U}$ codons additionally contain paromomycin, which was added to enhance the diffraction properties of these complexes (Supplemental Fig. S1). As expected, the structures containing paromomycin also display the same characteristic cognate interactions as the 70S-ACC-A structure lacking paromomycin. Therefore, since all three structures contain the same A-site interactions between the ACC codon and the anticodon, this provides strong evidence that all three +1 suppressible codons are recognized as cognate by the ribosome.

To accurately compare ASL ${ }^{\text {Suff }}$ to other ASLs that contain seven nucleotide anticodon loops, we solved two additional $70 S$ complexes containing ASL ${ }^{\text {Thr }}$ bound to either ACC-A or ACC- $\underline{C}$ codons in the A site of the 70S Tth ribosome to
3.6 Å resolution (Supplemental Fig. S4; Table 2). Both structures also contained paromomycin. These two codons were selected because of the approximately twofold higher affinity of both ASL ${ }^{\text {Suff }}$ and $\mathrm{ASL}^{\mathrm{Thr}}$ for the ACC-A codon as compared with the ACC-C codon (Fig. 3; Table 1). Unbiased $F_{\mathrm{o}}-F_{\mathrm{c}}$ difference electron density maps showed a clear signal for mRNA, P-site tRNA ${ }^{\mathrm{fMet}}$, and A-site $\mathrm{ASL}^{\mathrm{Thr}}$ nucleotides 28-43. Structural analyses revealed that $\mathrm{ASL}^{\mathrm{Thr}}$ recognizes both ACC- $\underline{A}$ and ACC- $\underline{C}$ codons in the zero frame as cognate, with A1492, A1492, and G530 interacting with the first two base pairs of codon-anticodon helix.

\section{The C31.5 insertion in ASL ${ }^{\text {Suff }}$ results in conformational rearrangements in the stem of the ASL}

The C31.5 insertion in tRNA ${ }^{\text {Suff }}$ was previously predicted to form a new stacking interaction with U32 allowing a widening of the unpaired loop of the ASL, while preserving the anticodon structure (Bossi and Smith 1984). Our results indicate that the anticodon loop nucleotides 33-37 are superimposable with other ASLs containing seven nucleotides, including ASL $^{\text {Thr }}$ (Fig. 4B). The C31.5 insertion neither forces a bulge in the stem to allow for stacking with U32 nor causes a widening of the loop; in fact, the loop of $\mathrm{ASL}^{\text {Suff }}$ is narrower than normal ASLs (Figs. 4B, 5A). In contrast, large, concerted movements of both the $5^{\prime}$ and $3^{\prime}$ phosphate backbone of the anticodon stem facilitate accommodation of the 

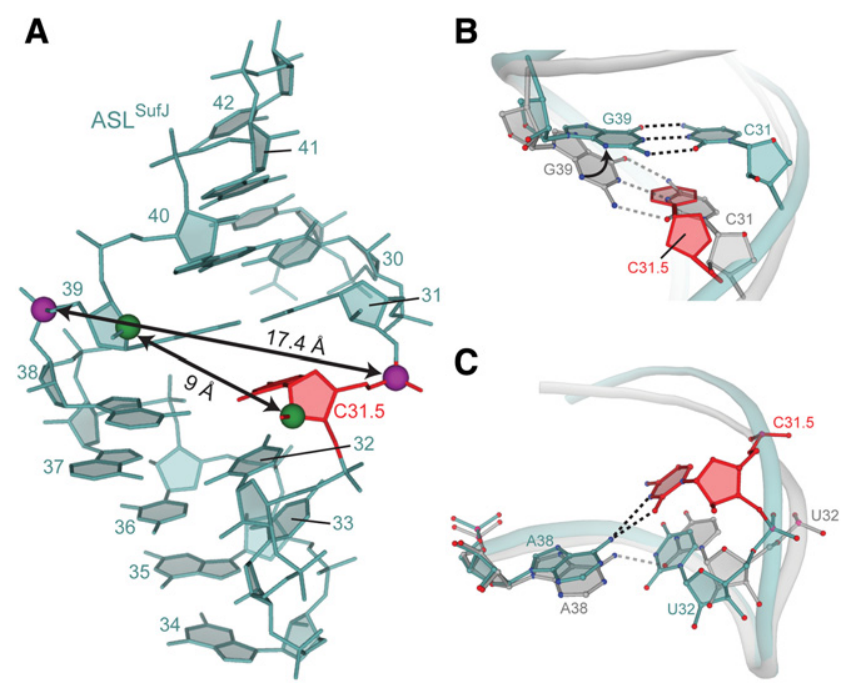

FIGURE 5. Narrowing of ASL ${ }^{\text {Suff }}$ alters anticodon stem base-pair interactions. (A) Both the major (as measured by C31.5.G39 phosphatephosphate distances; purple spheres) and minor grooves (as measured by $\mathrm{C} 31.5 \cdot \mathrm{G} 39 \mathrm{C} 2^{\prime}-\mathrm{C} 2^{\prime}$ distances; green spheres) are narrowed in $\mathrm{ASL}^{\text {SufJ }}$ as compared with canonical major and minor groove distances of $18.4 \AA$ and $14.2 \AA$, respectively (e.g., $\mathrm{ASL}^{\mathrm{Thr}}$ ). The C31.5 insertion is shown as red. (B) The C31.5 insertion (red) causes C31 in $\mathrm{ASL}^{\text {Suff (blue) }}$ to shift in the $5^{\prime}$ direction; however, the interaction with G39 (blue) is maintained via a $25^{\circ}$ rotation of its base around the glycosidic bond. The canonical C31-G39 interaction of a canonical seven-nucleotide $\mathrm{ASL}^{\mathrm{Thr}}$ is shown for comparison (gray). (C) The $5^{\prime}$ phosphate backbone movement shifts U32 (blue) closer to the opposite RNA stem while A38 rotates $8^{\circ}$ to form a bifurcated hydrogen bond with the inserted C31.5 (red). This new interaction prevents the formation of the conserved $\mathrm{U} 32 \cdot \mathrm{A} 38$ base pair of $\mathrm{ASL}^{\mathrm{Thr}}$ (gray).

C31.5 insertion (Fig. 4B). The $5^{\prime}$ stem, in which C31.5 is located, displaces the phosphate backbone by $\sim 4 \AA$ toward the $3^{\prime}$ ASL stem (Fig. 4B). Likewise, the $3^{\prime}$ stem undergoes an even larger displacement of $\sim 7 \AA$ in the same direction away from the $5^{\prime}$ stem. These combined conformational rearrangements result in the tilting of the anticodon stem $\sim 11.5^{\circ}$ away from the P-site tRNA ${ }^{\mathrm{fMet}}$, toward the back of the $30 \mathrm{~S}$ A site (Fig. 4B).

The concerted movement of the anticodon stems of ASL ${ }^{\text {Sufj }}$ narrows the major groove from 18.4 to $17.4 \AA$ (phosphatephosphate distances) and the minor groove from 14.2 to $9 \AA$ ( $2^{\prime}-\mathrm{C}_{2}^{\prime}$ distances) (Fig. 5A). Collectively, these changes cause a reduction in the average base-pair incline (or the angle between the base pairs) and the helical axis from $14^{\circ}$ in $\mathrm{ASL}^{\mathrm{Thr}}$ to $11.5^{\circ}$ in $\mathrm{ASL}^{\text {Sufj }}$ with a concomitant increase in the overall helical twist $\left(29^{\circ}\right.$ in $\mathrm{ASL}^{\mathrm{Thr}}$ versus $33^{\circ}$ in $\left.\mathrm{ASL}^{\mathrm{SufJ}}\right)$. An additional consequence of the ASL stem rotation toward the back of the A site, is that this movement prevents a conserved interaction between Lys 121 of ribosomal protein S13 and the $2^{\prime}-\mathrm{OH}$ of G40. While the electron density of the Lys121 side chain is not interpretable, the conformational rearrangement of nucleotide G40 of ASL ${ }^{\text {Suff }}$ would prevent any possibility of forming a hydrogen bonding interaction with this residue given the larger distance.

\section{Anticodon stem register is maintained in $\mathrm{ASL}^{\text {SufJ }}$ despite alteration of the conserved 32-38 base pair}

The C31.5 nucleotide occupies the physical position of C31 in the 70S-ASL ${ }^{\text {Thr }}$ structures, thereby shifting the $5^{\prime}$ side of the ASL ${ }^{\text {Sufj }}$ stem by one nucleotide (Fig. 5A). However, the base-pair register is maintained with the opposite side of the stem via a rotation of the G39 base $\left(25^{\circ}\right)$ about its N-glycosidic bond (Fig. 5B). While this change in torsion angle preserves the C31-G39 interaction of the stem, it disrupts the conserved U32.A38 base pair (Fig. 5C). Although the position of U32 is largely consistent between the 70S-ASL ${ }^{\mathrm{Thr}}$ and $70 \mathrm{~S}-\mathrm{ASL}^{\text {Suff }}$ structures, A38 rotates $8^{\circ}$ to form a new bifurcated hydrogen bond between its $\mathrm{N} 6$ position and both the $\mathrm{N} 3$ and $\mathrm{O} 2$ atoms of the inserted C31.5 (Fig. 5C). The C31.5 insertion in $\mathrm{ASL}^{\text {SufJ }}$ structurally replaces the U32 in the $\mathrm{U} 32 \cdot \mathrm{A} 38$ interaction as seen in $\mathrm{ASL}^{\mathrm{Thr}}$, therefore forming a new C31.5·A38 pair (Fig. 5C).

\section{Projection of tRNA ${ }^{\text {SufJ }}$ in the $A$ and $P$ sites indicates potential rearrangements due to steric clashes}

Previously determined 70 S and 30 S structures containing Asite tRNAs or ASLs, all contain anticodon stem-loops that adopt a conformation that closely approximates an accommodated or pre-peptidyl transferase state (Voorhees et al. 2009). However, in special cases such as an insertion in the anticodon or modifications at nucleotide 34, the A-site ASL can adopt an alternate conformation but only at the anticodon or the unpaired anticodon loop (Murphy et al. 2004; Phelps et al. 2006; Cantara et al. 2013). The conformational changes of the anticodon stem that we observe in $\mathrm{ASL}^{\text {Sufj }}$ have never been seen previously in any 70S structure. To understand how the $11.5^{\circ}$ tilt would affect the position of $\mathrm{ASL}^{\text {Suff }}$ in the context of a full-length tRNA, we aligned the anticodons of ASL ${ }^{\text {Suf }}$ and $\mathrm{tRNA}^{\mathrm{Phe}}$ (PDB code $2 \mathrm{WDH}$ ) and then projected a fulllength tRNA ${ }^{\text {Suff }}$ using fully accommodated Phe-tRNA ${ }^{\text {Phe }}$ as a guide (Fig. 6A; Voorhees et al. 2009). This alignment revealed the tilted stem domain of $\mathrm{ASL}^{\mathrm{SufJ}}$ repositions the acceptor arm $>20 \AA$ distant from the position of a canonical accommodated state tRNA. Moreover, tRNA ${ }^{\text {Suff }}$ would clash with components of the 50S (Fig. 6A). Clearly tRNA ${ }^{\text {Suff }}$ does not bind in this manner to the 70S and must instead undergo structural remodeling to be positioned properly for tRNA accommodation and peptide bond formation. In summary, the $11.5^{\circ}$ tilt of the anticodon stem of ASL ${ }^{\text {Suf }}$ suggests that the C31.5 insertion changes the energetic landscape that governs the transition of tRNA between its various functional conformations.

In the 30S A site, the ribosome exclusively interacts with the anticodon of the tRNA to ensure high fidelity tRNA selection. Upon translocation to the P site by EF-G, the anticodon is no longer closely monitored. Instead, the ribosome interacts with the anticodon stem and other regions of the tRNA body to optimally orient the acceptor arm for peptide bond 


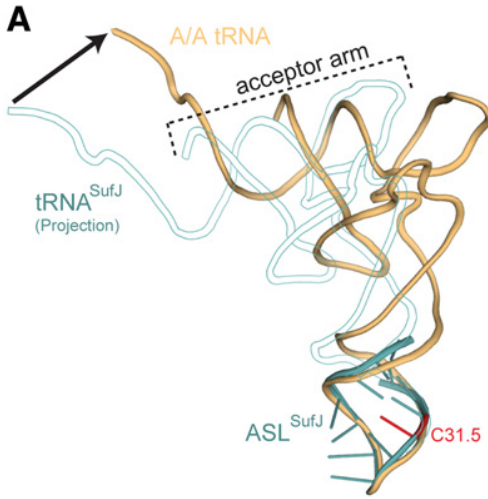

B
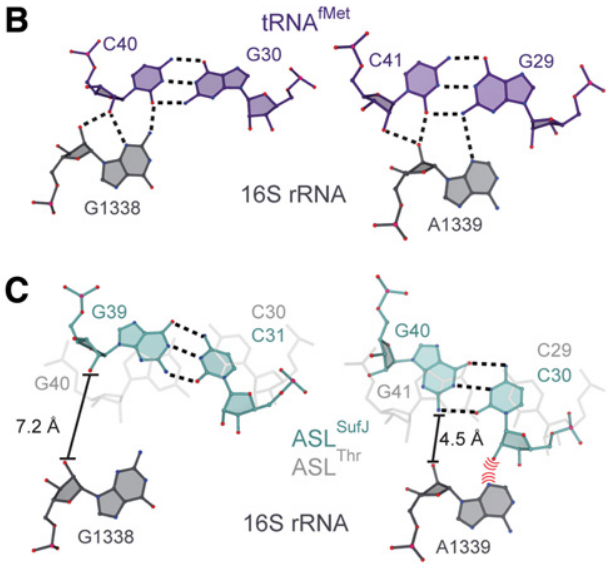

FIGURE 6. Modeling tRNA ${ }^{\text {Suff }}$ interactions in the A and P sites. (A) Modeling studies extending our structure of $\mathrm{ASL}^{\text {Suff }}$ (blue) to a full-length $\mathrm{tRNA}^{\text {Suff }}$ (white outlined with blue) reveal that the tilting position of the stem region would result in the CCA end of tRNA ${ }^{\text {Suff }}>20 \AA$ distant from the position of an accommodated A-site tRNA (gold) (arrow at the CCA end indicates the difference). We predict that conformational rearrangements of $\mathrm{tRNA}^{\text {Suff }}$ are required to prevent this interaction with the ribosome. $(B)$ The P-site tRNA ${ }^{\text {fMet }}$ (purple) is gripped by 16S rRNA G1338 and A1339 (gray) by the formation of A-minor interactions with both C40-G30 and C41-G29 (PDB code 2J02). (C) Superposition of ASL ${ }^{\text {Suff }}$ on the anticodon of $\mathrm{tRNA}^{\mathrm{fMet}}$ in the P site suggests that the deformation of the stem domain would prevent the formation of canonical G1338 and A1339 interactions. A semitransparent overlay of the superpositioning of ASL ${ }^{\text {Thr }}$ is shown for comparison (light gray).

formation. It has been proposed that the $\mathrm{P}$ site has evolved to tightly grip the tRNA in order to maintain the proper mRNA reading frame (Selmer et al. 2006; Atkins and Bjork 2009; Nasvall et al. 2009; Jager et al. 2013). For example, initiator tRNA $^{\text {fMet }}$ is "gripped" by 16S rRNA residues G1338 and A1339 through A-minor motif interactions with anticodon stem base pairs (Fig. 6B; Lancaster and Noller 2005; Selmer et al. 2006). Superpositioning of A-site ASL ${ }^{\text {SufJ }}$ into the $\mathrm{P}$ site by alignment of the anticodon to tRNA ${ }^{\mathrm{fMet}}$ reveals the $5^{\prime}$ stem adjacent to the insertion site and the C31.5 phosphate would sterically clash with $16 \mathrm{~S}$ rRNA residue A1339. However, the twist in the ASL ${ }^{\text {Suff }}$ stem prevents the formation of A-minor interactions with 16S rRNA nucleotide G1338 (Fig. 6C). This predicted lack of interaction indicates that either the gripping of the anticodon stem of tRNA ${ }^{\text {Suff }}$ is different from wild-type tRNAs or a conformational rearrangement of the stem occurs. The remodeling of the anticodon stem could possibly occur during translocation or after translocation into the $\mathrm{P}$ site, which in turn, facilitates the movement of mRNA by one nucleotide into the +1 frame.

\section{DISCUSSION}

Extragenic +1 frameshift suppressors were predominately identified as nucleotide insertions in the anticodon loops of tRNAs (for review, see Atkins and Bjork 2009). Although one interpretation of this phenomenon was that efficiency of +1 frameshifting was dependent on the Watson-Crick complementarity between the insertions located in both the tRNA and codon, the identification of tRNA ${ }^{\text {Suff }}$ necessitated alternative hypotheses (Bossi and Smith 1984; Farabaugh 2000). While tRNA ${ }^{\text {Suff }}$ does contain an insertion in its anticodon loop, the extra nucleotide is located adjacent to the anticodon stem, distal from the anticodon and therefore it was unclear whether this insertion actually expanded the anticodon to more than three nucleotides. The structures here reveal that ASL $^{\text {SufJ }}$ binds to three +1 suppressible codons in the zero frame allowing only a three-nucleotide codon-anticodon cognate interaction in the A site. The C31.5 insertion does not appear to alter the structural integrity of the ASL in the same manner as other frameshift suppressors where disordering of the conserved $U$ turn, the entire $5^{\prime}$ stem or nucleotide 32 occurs (Phelps et al. 2006; Dunham et al. 2007; Maehigashi et al. 2014). Instead, ASL ${ }^{\text {Suff }}$ accommodates the insertion through concerted movements of both the $5^{\prime}$ and $3^{\prime}$ phosphate backbones of the anticodon stem, causing a reorganization of key nucleotide interactions in the anticodon loop. These results indicate that insertions either $5^{\prime}$ or $3^{\prime}$ of the anticodon that result in +1 frameshifting may adopt different structural changes with an underlying theme being that tRNA plasticity, rather than the codon-anticodon interaction, drives +1 frameshifting.

Our 70S-A-site ASL ${ }^{\text {Suff }}$ structures reveal that the C31.5 insertion does not widen the anticodon loop but, rather, causes a narrowing of both the major and minor grooves of the ASL. Narrowing of the anticodon loop was also observed in a recent 70 S structure containing an A-site +1 frameshift suppressor tRNA ${ }^{\text {SufA6 }}$ (Maehigashi et al. 2014). In this case, tRNA ${ }^{\text {SufA6 }}$ contains an insertion $3^{\prime}$ to the anticodon between nucleotides 37 and 38 , on the opposite side of the loop to

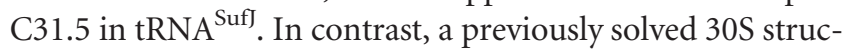
ture bound to a +1 frameshift suppressor ASL shows an insertion at 33.5 causes a widening of the loop (Dunham et al. 2007). It remains unclear whether a narrowing or a widening of frameshift suppressor tRNA anticodon loops indicates a different mechanism by which a +1 reading of the mRNA occurs. However, a common emerging theme is that insertions in the anticodon stem-loops of tRNAs are accommodated in different ways thus reinforcing the idea of structural plasticity as a driver of +1 frameshifting.

Although the reorganization of the anticodon loop interactions allows for maintenance of the base-pair registry in the anticodon stem, the major consequence of this preservation and the C31.5 insertion is that the identity of the 32-38 interaction is altered from U32.A38 to C31.5.A38. Anticodon stem nucleotides 32 and 38 are important for tRNA affinity and selection on the ribosome with the identity of this pair 
directly correlated to both the Watson-Crick base-pair strength of the codon-anticodon interaction and the aminoacyl group attached to the CCA $3^{\prime}$ end (Olejniczak and Uhlenbeck 2006; Ledoux and Uhlenbeck 2008). A strong C32.A38 interaction is predicted to counteract a weak codon-anticodon interaction such as in the case of tRNA ${ }^{\text {Lys }}$ (UUU), whereas a weak U32.A38 interaction is normally paired with a strong codon-anticodon interaction such as in the case of tRNA ${ }^{\text {Pro }}$ (GGG) (Olejniczak and Uhlenbeck 2006). This correlation of the 32-38 identity and the codonanticodon strength allows for the fine tuning of tRNA selection by the ribosome. Surprisingly, compensatory mutations of the rare A32.U38 pair in tRNA ${ }^{\mathrm{Ala}}$ to the more common U32.A38 displayed no effects on tRNA binding or incorporation when decoding cognate codons (Ledoux et al. 2009). However, $\mathrm{tRNA}^{\mathrm{Ala}}$ with the common U32.A38 pair is more rapidly accommodated when a near-cognate codon is present in the A site, indicating a loss of fidelity. Additional evidence for the importance of the 32-38 pairing comes from tRNA suppressor experiments using an amber stop codon. Here, stop codon readthrough efficiencies were increased when 32-38 was mutated to a strong C32.A38 pair, again strongly suggesting a loss of fidelity (Yarus et al. 1986a,b; Kleina et al. 1990; McClain et al. 1998; Tsai et al. 1998). We predict that, in general, the insertion of a nucleotide within an anticodon loop reduces its binding affinity to the ribosomal A site. However, in the case of ASL ${ }^{\text {Suff }}$ where the insertion results in the formation of a new, strong C31.5 $\cdot \mathrm{A} 38$ interaction, our interpretation is that the predicted lower affinity resulting from expanding the ASL to eight nucleotides is counterbalanced by the increased strength of the 31.5 .38 interaction. Indeed, our affinity measurements with ASL/ tRNA $^{\text {Suff }}$ indicate that the C31.5 insertion slightly increases A-site affinity as compared with wild-type ASL/tRNA ${ }^{\text {Thr }}$. Likewise we would predict that if $\mathrm{C} 31.5$ were mutated to an uridine resulting in a U31.5.A39 pairing, the binding affinity for this weaker pairing in the ribosomal A site would be reduced.

Our results examining ASL ${ }^{\text {Suf }}$ in light of our recent studies of ASL ${ }^{\text {SufA6 }}$ (Maehigashi et al. 2014) lead us to propose that +1 frameshifting by these suppressors does not occur by quadruplet decoding in the A site. Although the structures of $\mathrm{ASL}^{\text {Suff }}$ and ASL ${ }^{\text {SufA6 }}$ indicate the insertions alter the anticodon loops in distinct manners, both structures involve either the rearrangement or disruption of the 32-38 pair. This reorganization of the 32-38 pairing occurs despite $\mathrm{ASL}^{\text {Suff }}$ forming a cognate interaction while $\mathrm{ASL}^{\mathrm{SufA} 6}$ forms a nearcognate interaction with their +1 suppressible codons in the A site. What remains unclear is if the frameshift occurs during translocation or after translocation of the mRNAtRNA pair to the $\mathrm{P}$ site. Unlike $\mathrm{ASL}^{\mathrm{SufA}}{ }^{\text {, }}$, the $5^{\prime} \mathrm{ASL}^{\text {Suff }}$ stem nucleotide 32 is ordered. Disordering may be an important stimulus for the +1 frameshift event because EF-G directly interacts with the $5^{\prime}$ stem in the A site before translocation (Brilot et al. 2013). Interestingly, the narrowing of the stem and $11.5^{\circ}$ tilting of $\mathrm{ASL}^{\text {Suff }}$ suggests that adjustment of P-site interactions with conserved 16S rRNA nucleotides G1338 and A1339 could occur upon translocation. Another possibility is that $\mathrm{ASL}^{\text {Suff }}$ would be required to undergo a conformational rearrangement of its anticodon loop to maintain this important gripping interaction, which could then facilitate the shifting into the new +1 mRNA reading frame. Taken together, these results help to begin to unravel mechanistic details of +1 frameshifting.

\section{MATERIALS AND METHODS}

\section{E. coli ribosome purification}

$70 \mathrm{~S}$ ribosomes were purified as previously described with a few modifications (Powers and Noller 1991). Briefly, E. coli MRE600 cells were grown in $\mathrm{LB}$ to an $\mathrm{OD}_{600}$ of $0.6-0.8$ and then cooled on ice for $20 \mathrm{~min}$ to increase the concentration of run-off $70 \mathrm{~S}$ ribosomes. Cultures were then pelleted and resuspended in buffer A (20 mM HEPES pH 7.5, $100 \mathrm{mM} \mathrm{NH}_{4} \mathrm{Cl}, 10.5 \mathrm{mM}$ MgOAc, 0.5 mM EDTA, $0.1 \mathrm{mM}$ benzamidine, $0.1 \mathrm{mM}$ phenylmethanesulfonylfluoride (PMSF) and $6 \mathrm{mM} \beta$-mercaptoethanol $(\beta-\mathrm{Me}))$ and lysed using a EmulsiFlex cell disruptor. The lysate was clarified by centrifugation $(30 \mathrm{~min}$ at $70,000 \mathrm{~g}$ ) and pelleted over a sucrose cushion (1.1 M sucrose, $20 \mathrm{mM}$ HEPES pH 7.5, $500 \mathrm{mM} \mathrm{NH}_{4} \mathrm{Cl}, 10.5$ $\mathrm{mM}$ MgOAc, $0.5 \mathrm{mM}$ EDTA) for $17 \mathrm{~h}$ at $158,000 \mathrm{~g}$ at $4^{\circ} \mathrm{C}$. The ribosome pellet was resuspended in buffer $\mathrm{C}(20 \mathrm{mM}$ Tris- $\mathrm{Cl} \mathrm{pH}$ 7.5, $400 \mathrm{mM} \mathrm{KCl}, 10 \mathrm{mM} \mathrm{MgOAc}, 1.5 \mathrm{M}\left(\mathrm{NH}_{4}\right)_{2} \mathrm{SO}_{4}, 0.1 \mathrm{mM}$ benzamidine, $0.1 \mathrm{mM}$ PMSF, and $6 \mathrm{mM} \beta-\mathrm{Me}$ ) and purified over a Butyl$650 \mathrm{~S}$ HIC column (Toyopearl) using a reverse $\left(\mathrm{NH}_{4}\right)_{2} \mathrm{SO}_{4}$ gradient. $70 \mathrm{~S}$ ribosomes were further separated over a 10\%-40\% sucrose gradient in buffer $\mathrm{E}$ (10 mM HEPES pH 7.5, $50 \mathrm{mM} \mathrm{KCl,} 10 \mathrm{mM}$ $\mathrm{NH}_{4} \mathrm{Cl}, 10.25 \mathrm{mM}$ MgOAc, 0.25 mM EDTA, $0.1 \mathrm{mM}$ benzamidine, $0.1 \mathrm{mM}$ PMSF and $6 \mathrm{mM} \beta-\mathrm{Me})$. Fractions were pooled and concentrated by pelleting over a sucrose cushion, resuspended and dialyzed overnight in buffer G (5 mM HEPES pH 7.5, $50 \mathrm{mM} \mathrm{KCl,} 10$ $\mathrm{mM} \mathrm{NH}_{4} \mathrm{Cl}, 10 \mathrm{mM} \mathrm{MgOAc}$, and $6 \mathrm{mM} \beta-\mathrm{Me}$ ). Lastly, purified $70 \mathrm{~S}$ ribosomes were concentrated using an Amicon $100 \mathrm{~K}$ molecular weight cut-off concentrator (Millipore) and stored at $-80^{\circ} \mathrm{C}$.

\section{In vitro transcription}

Salmonella typhimurium tRNA $^{\text {SufJ }}$, along with a $5^{\prime}$ T7 promoter site, were subcloned into a pUC19 vector using overlapping DNA oligos (IDT). Plasmid overexpression, purification and in vitro transcription reactions were performed as previously described using BstNI (NEB) to linearize the plasmid (Linpinsel and Conn 2012). The $5^{\prime}$ triphosphate was removed by Calf Intestinal Phosphatase (NEB) and purified by phenol-chloroform and chloroform extractions followed by ethanol precipitation and stored in Tris-EDTA buffer (10 mM Tris- $\mathrm{HCl} \mathrm{pH} 8.0,1 \mathrm{mM}$ EDTA) at $-20^{\circ} \mathrm{C}$. For the Salmonella typhimurium RNA $^{\mathrm{Thr}}$, we encountered difficulties purifying tRNA ${ }^{\text {Thr }}$ away from a contaminating RNA band of a similar size after in vitro transcription. Therefore we PCR amplified the $\mathrm{tRNA}^{\text {Thr }}$ gene and a $5^{\prime} \mathrm{T} 7$ promoter site from overlapping DNA oligos (IDT) and purified the in vitro transcribed RNA product as previously described (Linpinsel and Conn 2012). 


\section{RNA sequences}

The mRNA sequence used in both the filter binding experiments and crystallization trials was $5^{\prime}$-GGCAAGGAGGUAAAAA UGACC HAAA-3', where $\mathrm{H}$ represents an A, $\mathrm{U}$, or $\mathrm{C}$ nucleotide (threonine codon is in bold and follows the italicized AUG start site). ASL ${ }^{\text {Thr }}$ sequence was $5^{\prime}$-CACCCUUGGUAAGGGUG-3' and for ASL ${ }^{\text {Suff }}$ was $5^{\prime}$-CACCCCUUGGUAAGGGUG- ${ }^{\prime}$ where the anticodon is underlined and nucleotide insertion in $\mathrm{ASL}^{\mathrm{Suff}}$ is indicated in bold (IDT).

\section{5'-Labeling of ASLs and tRNAs}

tRNAs or ASLs $(1 \mu \mathrm{M})$ were incubated with $\left[\gamma^{-32} \mathrm{P}\right]$-ATP $(1 \mu \mathrm{Ci} / \mu \mathrm{L}$, $3000 \mathrm{Ci} / \mathrm{mmol}$, PerkinElmer) and T4 polynucleotide kinase (NEB) for $1 \mathrm{~h}$ at $37^{\circ} \mathrm{C}$. Free nucleotide was removed by purification over a Sephadex G-25 spin column (GE Healthcare) and the labeling efficiency was determined by scintillation counting (Beckman LS-5000TD). A typical filter binding reaction contained 200,000$700,000 \mathrm{cpm} / \mu \mathrm{L}$ of tRNA or ASL. Labeled tRNA or ASL were stored at a concentration of $10 \mu \mathrm{M}$ at $-20^{\circ} \mathrm{C}$.

\section{5 binding assays}

The affinity of tRNAs or ASLs for the 70S A site was measured using filter binding assays as previously described (Olejniczak et al. 2005). Briefly, purified E. coli 70 S ribosomes $(500 \mathrm{nM})$ were incubated with mRNA $(1 \mu \mathrm{M})$ in buffer $\mathrm{G}$ at $37^{\circ} \mathrm{C}$ for $5 \mathrm{~min}$, followed by the addition of P-site tRNA ${ }^{\mathrm{fMet}}(1 \mu \mathrm{M})$ at $37^{\circ} \mathrm{C}$ for $30 \mathrm{~min}$. For some experiments as indicated, paromomycin $(100 \mu \mathrm{M})$ was incubated for an additional $25 \mathrm{~min}$ at room temperature. Twofold dilutions were made, resulting in a range of ribosome concentrations from 0.98 to $1 \mu \mathrm{M}$ which was experimentally determined to provide full coverage of the equilibrium dissociation curve; overall the ribosome concentration range were measured from $5 \mathrm{nM}$ to $1 \mu \mathrm{M}$. A-site tRNA ( $2 \mathrm{nM}$ ) or ASL $(2 \mathrm{nM})$ was added to each solution and the reaction was allowed to come to equilibrium at room temperature. A 3-h incubation was required for tRNA binding to reach equilibrium, however with the addition of paromomycin only a $2 \mathrm{~h}$ incubation was necessary. The ribosome reaction $(30 \mu \mathrm{L})$ was then filtered through a $0.45 \mu \mathrm{m}$ nitrocellulose membrane and washed with buffer $\mathrm{G}(1 \mathrm{~mL})$. The nitrocellulose filters were dissolved in Filtron-X (National Diagnostics) and counted using a Beckman LS-5000TD scintillation counter. Dissociation constants $\left(K_{\mathrm{D}}\right)$ and $B_{\max }$ values were obtained by fitting the data to a one site specific binding nonlinear regression using GraphPad Prism as has been done for previous equilibrium binding experiments (Ledoux and Uhlenbeck 2008).

\section{$70 S$ complex formation and crystallization}

Thermus thermophilus ribosomes were purified and crystallization trials were performed as previously described with a few minor modifications (Selmer et al. 2006). Briefly, 70S ribosomes $(4.4 \mu \mathrm{M})$ were incubated with CC-puromycin (Dharmacon; $22 \mu \mathrm{M}$ ), an aminoacyl mimic consisting of the RNA dinucleotide CC covalently attached to puromycin $-5^{\prime}$-monophosphate, for $30 \mathrm{~min}$ at $55^{\circ} \mathrm{C}$. This was followed by incubation with a two molar excess of mRNA (IDT; $8.8 \mu \mathrm{M}$ ) for $5 \mathrm{~min}$. Four molar excess of P-site tRNA ${ }^{\mathrm{fMet}}$ (Chemical Block; $17.6 \mu \mathrm{M}$ ) was incubated for $30 \mathrm{~min}$ at $55^{\circ} \mathrm{C}$ and finally, five molar excess of the appropriate ASL (IDT; $22 \mu \mathrm{M}$ ) was incubated for $30 \mathrm{~min}$ at $55^{\circ} \mathrm{C}$. The complexes were cooled to room temperature and then incubated with antibiotic paromomycin $(0.1 \mathrm{mM})$ for an additional $20 \mathrm{~min}$ at room temperature. Deoxy BigCHAP (Hampton Research; $2.8 \mu \mathrm{M}$ ) was added just prior to crystallization. Crystals were grown by sitting-drop vapor diffusion in 4\%-5\% polyethylene glycol (PEG) 20K, 4\%-5\% PEG 550 MME, 0.1 M Tris-Acetate pH 7.0, 0.2 M KSCN and $10 \mathrm{mM}$ $\mathrm{MgCl}_{2}$, and cryoprotected by increasing PEG $550 \mathrm{MME}$ in a stepwise manner to a final concentration of $30 \%$. Crystals were flash frozen in liquid nitrogen for data collection.

\section{$\mathrm{X}$-ray data collection and structure determination}

X-ray diffraction data were collected at the Southeast Regional Collaborative Access Team (SER-CAT) 22-ID beamline and the Northeastern Collaborative Access Team (NE-CAT) 24-IDC beamline at the Advanced Photon Source, Argonne National Laboratory. Each data set was integrated and scaled using the XDS software package (Kabsch 2010). A search model composed of the Tth $70 S$ ribosome (PDB codes 2WDG, 2WDH, 2WDI, and 2WDJ) with all mRNA and tRNA ligands removed was used for crystallographic refinement with the PHENIX software suite (Adams et al. 2010). Additional rounds of coordinate refinement were performed with rigid groups defined by the head, body, platform, and 3 '-minor domain of the $30 \mathrm{~S}$ subunit, along with mobile elements of the $50 \mathrm{~S}$ subunit: 5S rRNA, L1 arm, protein L9, A-site finger, and the central protuberance. Modeling of mRNA, tRNA, and conformational changes in rRNA and ribosomal proteins along with the placement $\mathrm{Mg}^{2+}$ ions were performed using Coot (Emsley et al. 2010). Iterative rounds of model building were followed by positional and group atomic displacement parameter (ADP) refinement in PHENIX, yielding a final model with the statistics reported in Table 2. Figures were generated using PyMOL (www.pymol.org).

\section{DATA DEPOSITION}

The atomic coordinates and structure factors have been deposited in the Protein Data Bank (www.pdb.org) under the PDB codes 4TUA, 4TUB, 4TUC, 4TUD, and 4TUE.

\section{SUPPLEMENTAL MATERIAL}

Supplemental material is available for this article.

\section{ACKNOWLEDGMENTS}

Support for this work was provided by the Department of Defense through the National Defense Science and Engineering Graduate Fellowship Program and National Institutes of Health (NIH) Training Grant T32 GM8367 (to C.E.F.), and National Institute of General Medical Sciences of the NIH Award R01GM093278 (to C.M.D.). C.M.D. is a Pew Scholar in the Biomedical Sciences (Pew Charitable Trusts). We thank G.L. Conn and members of the Dunham lab for helpful discussions throughout the project and critical reading of the manuscript, and staff members at both SER-CAT and NE-CAT beamlines for assistance during data collection. This work is based on research conducted at the Advanced 
Photon Source on the NE-CAT beamlines (supported by National Center for Research Resources [NIH] Award RR-15301) and SERCAT beamline. Use of the Advanced Photon Source, an Office of Science User Facility operated for the US Department of Energy (DOE) Office of Science by Argonne National Laboratory, was supported by US DOE Contract DE-AC02-06CH11357.

Received August 6, 2014; accepted September 2, 2014.

\section{REFERENCES}

Adams PD, Afonine PV, Bunkoczi G, Chen VB, Davis IW, Echols N, Headd JJ, Hung LW, Kapral GJ, Grosse-Kunstleve RW, et al. 2010. PHENIX: a comprehensive Python-based system for macromolecular structure solution. Acta Crystallogr D Biol Crystallogr 66 (Pt 2): 213-221.

Anderson JC, Magliery TJ, Schultz PG. 2002. Exploring the limits of codon and anticodon size. Chem Biol 9: 237-244.

Atkins JF, Bjork GR. 2009. A gripping tale of ribosomal frameshifting: Extragenic suppressors of frameshift mutations spotlight P-site realignment. Microbiol Mol Biol Rev 73: 178-210.

Bossi L, Roth JR. 1981. Four-base codons ACCA, ACCU and ACCC are recognized by frameshift suppressor sufJ. Cell 25: 489-496.

Bossi L, Smith DM. 1984. Suppressor suf): a novel type of tRNA mutant that induces translational frameshifting. Proc Natl Acad Sci 81: 61056109.

Bouadloun F, Donner D, Kurland CG. 1983. Codon-specific missense errors in vivo. EMBO J 2: 1351-1356.

Brilot AF, Korostelev AA, Ermolenko DN, Grigorieff N. 2013. Structure of the ribosome with elongation factor $\mathrm{G}$ trapped in the pretranslocation state. Proc Natl Acad Sci 110: 20994-20999.

Cantara WA, Murphy FV IV, Demirci H, Agris PF. 2013. Expanded use of sense codons is regulated by modified cytidines in tRNA. Proc Natl Acad Sci 110: 10964-10969.

Cummins CM, Donahue TF, Culbertson MR. 1982. Nucleotide sequence of the SUF2 frameshift suppressor gene of Saccharomyces cerevisiae. Proc Natl Acad Sci 79: 3565-3569.

Curran JF, Yarus M. 1987. Reading frame selection and transfer RNA anticodon loop stacking. Science 238: 1545-1550.

Demeshkina N, Jenner L, Westhof E, Yusupov M, Yusupova G. 2013. New structural insights into the decoding mechanism: translation infidelity via a G.U pair with Watson-Crick geometry. FEBS Lett 587: $1848-1857$.

Dunham CM, Selmer M, Phelps SS, Kelley AC, Suzuki T, Joseph S, Ramakrishnan V. 2007. Structures of tRNAs with an expanded anticodon loop in the decoding center of the $30 \mathrm{~S}$ ribosomal subunit. RNA 13: 817-823.

Edelmann P, Gallant J. 1977. Mistranslation in E. coli. Cell 10: 131-137.

Emsley P, Lohkamp B, Scott WG, Cowtan K. 2010. Features and development of Coot. Acta Crystallogr D Biol Crystallogr 66(Pt 4): 486-501.

Farabaugh PJ. 2000. Translational frameshifting: implications for the mechanism of translational frame maintenance. Prog Nucleic Acid Res Mol Biol 64: 131-170.

Gaber RF, Culbertson MR. 1984. Codon recognition during frameshift suppression in Saccharomyces cerevisiae. Mol Cell Biol 4: 2052-2061.

Hohsaka T, Ashizuka Y, Taira H, Murakami H, Sisido M. 2001. Incorporation of nonnatural amino acids into proteins by using various four-base codons in an Escherichia coli in vitro translation system. Biochemistry 40: 11060-11064.

Jager G, Nilsson K, Bjork GR. 2013. The phenotype of many independently isolated +1 frameshift suppressor mutants supports a pivotal role of the P-site in reading frame maintenance. PLoS One 8: e60246.

Jorgensen F, Kurland CG. 1990. Processivity errors of gene expression in Escherichia coli. J Mol Biol 215: 511-521.
Jorgensen T, Siboska GE, Wikman FP, Clark BF. 1985. Different conformations of tRNA in the ribosomal P-site and A-site. Eur J Biochem 153: 203-209.

Kabsch W. 2010. XDS. Acta Crystallogr D Biol Crystallogr 66(Pt 2): 125-132.

Khade P, Joseph S. 2010. Functional interactions by transfer RNAs in the ribosome. FEBS Lett 584: 420-426.

Kleina LG, Masson JM, Normanly J, Abelson J, Miller JH. 1990. Construction of Escherichia coli amber suppressor tRNA genes. II. Synthesis of additional tRNA genes and improvement of suppressor efficiency. J Mol Biol 213: 705-717.

Kramer EB, Farabaugh PJ. 2007. The frequency of translational misreading errors in $E$. coli is largely determined by tRNA competition. $R N A$ 13: 87-96.

Kurland CG. 1992. Translational accuracy and the fitness of bacteria. Annu Rev Genet 26: 29-50.

Lancaster L, Noller HF. 2005. Involvement of 16 S rRNA nucleotides G1338 and A1339 in discrimination of initiator tRNA. Mol Cell 20: 623-632.

Ledoux S, Uhlenbeck OC. 2008. Different aa-tRNAs are selected uniformly on the ribosome. Mol Cell 31: 114-123.

Ledoux S, Olejniczak M, Uhlenbeck OC. 2009. A sequence element that tunes Escherichia coli $\mathrm{tRNA}_{\mathrm{GGC}}^{\mathrm{Ala}}$ to ensure accurate decoding. Nat Struct Mol Biol 16: 359-364.

Lee JW, Beebe K, Nangle LA, Jang J, Longo-Guess CM, Cook SA, Davisson MT, Sundberg JP, Schimmel P, Ackerman SL. 2006. Editing-defective tRNA synthetase causes protein misfolding and neurodegeneration. Nature 443: 50-55.

Linpinsel JL, Conn GL. 2012. General protocols for preparation of plasmid DNA template, RNA in vitro transcription, and RNA purification by denaturing PAGE. Methods Mol Biol 941: $43-58$.

Maehigashi T, Dunkle JA, Miles SJ, Dunham CM. 2014. Structural insights into +1 frameshifting promoted by expanded or modification-deficient anticodon stem loops. Proc Natl Acad Sci 111: $12740-12745$.

Manley JL, Gesteland RF. 1978. Suppression of amber mutants in vitro induced by low temperature. J Mol Biol 125: 433-447.

McClain WH, Schneider J, Bhattacharya S, Gabriel K. 1998. The importance of tRNA backbone-mediated interactions with synthetase for aminoacylation. Proc Natl Acad Sci 95: 460-465.

Moore B, Persson BC, Nelson CC, Gesteland RF, Atkins JF. 2000. Quadruplet codons: implications for code expansion and the specification of translation step size. J Mol Biol 298: 195-209.

Murphy FV IV, Ramakrishnan V, Malkiewicz A, Agris PF. 2004. The role of modifications in codon discrimination by tRNA ${ }_{\text {UUU. }}^{\text {Lys }}$ Nat Struct Mol Biol 11: 1186-1191.

Nangle LA, De Crecy Lagard V, Doring V, Schimmel P. 2002. Genetic code ambiguity. Cell viability related to the severity of editing defects in mutant tRNA synthetases. J Biol Chem 277: 4572945733.

Nasvall SJ, Nilsson K, Bjork GR. 2009. The ribosomal grip of the peptidyl-tRNA is critical for reading frame maintenance. J Mol Biol 385: 350-367.

Ogle JM, Brodersen DE, Clemons WM Jr, Tarry MJ, Carter AP, Ramakrishnan V. 2001. Recognition of cognate transfer RNA by the 30 S ribosomal subunit. Science 292: 897-902.

Ogle JM, Murphy FV, Tarry MJ, Ramakrishnan V. 2002. Selection of tRNA by the ribosome requires a transition from an open to a closed form. Cell 111: 721-732.

Olejniczak M, Uhlenbeck OC. 2006. tRNA residues that have coevolved with their anticodon to ensure uniform and accurate codon recognition. Biochimie 88: 943-950.

Olejniczak M, Dale T, Fahlman RP, Uhlenbeck OC. 2005. Idiosyncratic tuning of tRNAs to achieve uniform ribosome binding. Nat Struct Mol Biol 12: 788-793.

Phelps SS, Jerinic O, Joseph S. 2002. Universally conserved interactions between the ribosome and the anticodon stem-loop of A site tRNA important for translocation. Mol Cell 10: 799-807. 
Phelps SS, Gaudin C, Yoshizawa S, Benitez C, Fourmy D, Joseph S. 2006. Translocation of a tRNA with an extended anticodon through the ribosome. J Mol Biol 360: 610-622.

Powers T, Noller HF. 1991. A functional pseudoknot in $16 \mathrm{~S}$ ribosomal RNA. EMBO J 10: 2203-2214.

Prather NE, Murgola EJ, Mims BH. 1981. Nucleotide insertion in the anticodon loop of a glycine transfer RNA causes missense suppression. Proc Natl Acad Sci 78: 7408-7411.

Qian Q, Li JN, Zhao H, Hagervall TG, Farabaugh PJ, Bjork GR. 1998. A new model for phenotypic suppression of frameshift mutations by mutant tRNAs. Mol Cell 1: 471-482.

Riddle DL, Carbon J. 1973. Frameshift suppression: a nucleotide addition in the anticodon of a glycine transfer RNA. Nat New Biol 242: 230-234.

Riddle DL, Roth JR. 1970. Suppressors of frameshift mutations in Salmonella typhimurium. J Mol Biol 54: 131-144.

Riddle DL, Roth JR. 1972. Frameshift suppressors. 3. Effects of suppressor mutations on transfer RNA. J Mol Biol 66: 495-506.

Riyasaty S, Atkins JF. 1968. External suppression of a frameshift mutant in salmonella. J Mol Biol 34: 541-557.

Rodnina MV. 2012. Quality control of mRNA decoding on the bacterial ribosome. Adv Protein Chem Struct Biol 86: 95-128.

Roth JR. 1974. Frameshift mutations. Annu Rev Genet 8: 319-346.

Selmer M, Dunham CM, Murphy FV IV, Weixlbaumer A, Petry S, Kelley AC, Weir JR, Ramakrishnan V. 2006. Structure of the 70S ribosome complexed with mRNA and tRNA. Science 313: 1935-1942.

Sherman F, Stewart JW, Jackson M, Gilmore RA, Parker JH. 1974. Mutants of yeast defective in iso-1-cytochrome c. Genetics 77: 255-284.
Tsai F, Curran JF. 1998. tRNA $_{2}$ Gln mutants that translate the CGA arginine codon as glutamine in Escherichia coli. RNA 4: 15141522.

von Ahsen U, Green R, Schroeder R, Noller HF. 1997. Identification of $2^{\prime}$-hydroxyl groups required for interaction of a tRNA anticodon stem-loop region with the ribosome. RNA 3: 49-56.

Voorhees RM, Weixlbaumer A, Loakes D, Kelley AC, Ramakrishnan V. 2009. Insights into substrate stabilization from snapshots of the peptidyl transferase center of the intact $70 \mathrm{~S}$ ribosome. Nat Struct Mol Biol 16: 528-533.

Walker SE, Fredrick K. 2006. Recognition and positioning of mRNA in the ribosome by tRNAs with expanded anticodons. J Mol Biol 360: 599-609.

Yarus M. 1982. Translational efficiency of transfer RNA's: uses of an extended anticodon. Science 218: 646-652.

Yarus M, Cline S, Raftery L, Wier P, Bradley D. 1986a. The translational efficiency of tRNA is a property of the anticodon arm. J Biol Chem 261: 10496-10505.

Yarus M, Cline SW, Wier P, Breeden L, Thompson RC. 1986b. Actions of the anticodon arm in translation on the phenotypes of RNA mutants. J Mol Biol 192: 235-255.

Yourno J. 1970. Nature of the compensating frameshift in the double frameshift mutant hisD3018 R5 of Salmonella typhimurium. J Mol Biol 48: 437-442.

Yourno J. 1972. Externally suppressible +1 "glycine" frameshift: possible quadruplet isomers for glycine and proline. Nat New Biol 239: 219-221.

Zaher HS, Green R. 2009. Fidelity at the molecular level: lessons from protein synthesis. Cell 136: 746-762. 

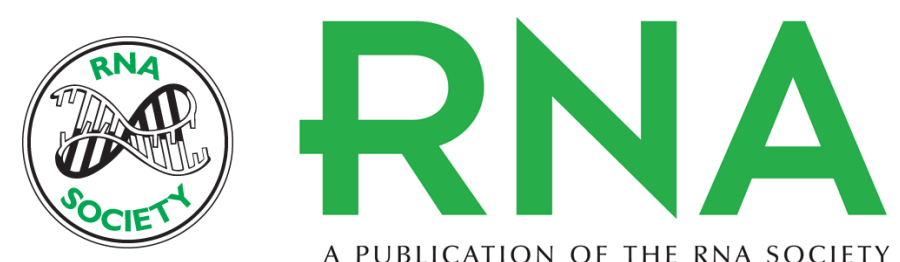

A PUBLICATION OF THE RNA SOCIETY

\section{Structural insights into translational recoding by frameshift suppressor tRNA}

Crystal E. Fagan, Tatsuya Maehigashi, Jack A. Dunkle, et al.

RNA 2014 20: 1944-1954 originally published online October 28, 2014

Access the most recent version at doi:10.1261/rna.046953.114

\section{Supplemental http://rnajournal.cshlp.org/content/suppl/2014/09/29/rna.046953.114.DC1 \\ Material}

References This article cites 64 articles, 20 of which can be accessed free at: http://rnajournal.cshlp.org/content/20/12/1944.full.html\#ref-list-1

Creative This article is distributed exclusively by the RNA Society for the first 12 months after the Commons License full-issue publication date (see http://rnajournal.cshlp.org/site/misc/terms.xhtml). After 12 months, it is available under a Creative Commons License (Attribution-NonCommercial 4.0 International), as described at http://creativecommons.org/licenses/by-nc/4.0/.

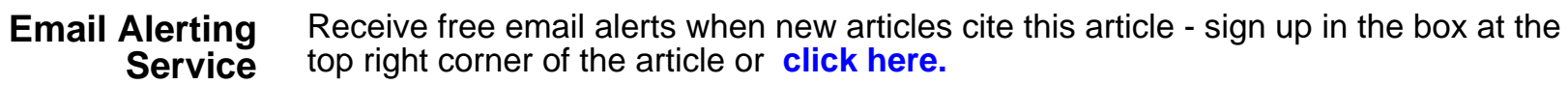

